\title{
APPLICATION OF NEW INFORMATION \\ AND TELECOMMUNICATION TECHNOLOGIES \\ IN RUSSIAN EDUCATIONAL MANAGEMENT
}

\author{
Evgeniya Yazovskikh ${ }^{1}$ \\ Oksana Yatsenko ${ }^{2}$
}

DOI: https://doi.org/10.31410/ITEMA.2019.155

\begin{abstract}
According to the state program "Information Society (2011-2020)", one of the priority areas in Russia is to improve the quality of education based on information technologies.

After adopting the new federal law "On Education in the Russian Federation", the development of new information and telecommunication technologies has become an urgent need. The law specifies the rules that allow educational institutions to use e-learning, distance learning technologies, and a network form for implementing educational programs. New information technologies in education have launched new opportunities: self-study, distance learning, tutoring, consulting, coaching.

Modern globalization of higher education, a two-tier system, the standards of the third generation and three plus actualize the problem of ensuring the quality of education, forming for the graduates a pool of competencies that meet the challenges of the labor market. The problem of the quality of training bachelors and masters, their postgraduate employment is of particular importance in connection with the orientation of educational institutions to the practical implementation of acquired competencies.
\end{abstract}

Keywords: Information Technologies, Educational Management, Telecommunication Technologies, Web-Quest.

\section{INTRODUCTION}

A present, the role of information technologies in people's lives has significantly increased. Modern society is involved in the general historical process, called informatization. This process includes the accessibility of any person to information sources, the penetration of information technologies into scientific, industrial, public spheres, a high level of information services.

The processes occurring in connection with informatization of society contribute not only to the acceleration of scientific and technical ones, intellectualization of all types of human activity, but also the creation of a qualitatively new information environment of the society that ensures the development of human creative potential.

One of the priorities of modern society is informatization of education, which is a system of methods, processes, software and hardware tools integrated to collect, process, store, distribute and use information in the interests of its consumers. The purpose of informatization is the global intensification of intellectual activity through the use of new information technologies: computer and telecommunication.

Ural federal University named after their first President of Russia B.N.Yeltsin, Mira str. 19, Yekaterinburg, 620002, Russia

2 Ural federal University named after their first President of Russia B.N.Yeltsin, Mira str. 19, Yekaterinburg, 620002, Russia 
According to Gorbunova and Subbotina (2013), information technologies provide the following opportunities: organizing the rational cognitive activity of learners during the educational process; making students study more effectively by involving them in a multimedia context and arming their intellect with new conceptual tools; building an open education system that provides each individual with their own learning path; involving in the process of active learning categories of students who differ in their abilities and learning style; using specific properties of the computer that help individualize the learning process and turn to fundamentally new cognitive tools; intensifying all levels of the educational process.

Altinentova and Rozhko (2016) confirm that computer technologies are designed to become an indispensable part of a holistic educational process that significantly increases its efficiency. As most researchers point out, the trends towards computerization of education will accelerate regardless of conditions.

Krasovskaya and Isaberova (2017) declare that today, the Ministry of Education of the Russian Federation pays great attention to informatization of the educational process, since the use of information technologies significantly increases the number of pedagogical teaching methods for students. In 2002, the Ministry of Education of the Russian Federation developed "The draft federal component of the state educational standard of general education in computer science and information technology".

Informatization of the educational space also determines the new approach to the organization of the educational process, to the methodological and didactic support. New methods and means of developing media education and information culture of students are needed.

A generation of Dot Com students has already been formed, for whom the perception of audiovisual information is more common than the printed one. Former readers gradually transformed into viewers with clip thinking.

Students often use Internet resources only by copying ready essays and course papers. Passive perception of information, consumer attitude to the media, plagiarism of texts, form stereotypical thinking, distorted outlook.

As Polat (2017) says: "For the development of a moral, creative, self-minded person, not only a much larger amount of information than that a teacher, a textbook, and teaching aids can provide, but a large variability of information, reflecting different points of view, different approaches to solving the same problems is required".

Modern educational practice requires the use of various methods of working with the information and communication environment. First of all, these are tasks for independent work of students based on Internet resources: a thematic list of references (Hotlist), a multimedia album (Multimedia Scrapbook), a collection of examples (Subject Sampler), a treasure hunt (Treasure / Scavenger Hunt).

A new format of textbooks for students, Smart textbooks is needed today. The problem of a "new generation textbook" as a means of increasing the effectiveness of training students, enhancing independent work through improvement in the comprehensibility of educational materials, and the ergonomic quality of educational material in recent decades has been intensively 
discussed in the pedagogical literature. Particularly relevant is the availability of such textbooks in universities where the integration of science and education takes place (Novikova, 2018).

One of the current and more complex working methods of students with Internet sources is a Web Quest. The concept of web quests was developed in the United States at the University of San Diego in the mid-1990s by professors B. Dodge and T. March. A web quest is the most difficult for both students and teacher.

The web quest is aimed at developing students' skills of analytical and creative thinking. A teacher who develops a web quest should have a high level of subject, methodical, and informational and communication competence.

As a part of the learning process, the topic of web quests can be diverse, problem tasks can be differentiated by degree of difficulty. The results of the web quest, depending on the material being studied, can be presented in the form of a web page, computer presentation, video journals, case study, essay, poster presentation, publication, and presentation at a conference.

A web quest is an educational website, a project dedicated to the independent research work of students (usually in groups) on a specific topic with references to various web pages. Its structure consists of several required sections:

1. introduction (theme, relevance and value of the project);

2. task (goal, objectives, conditions, problem and their optimal solution);

3. process (phased description of the work process, distribution of roles, responsibilities of each participant, Internet references, final product);

4. assessment (scale for self-assessment and evaluation of the work of group members, assessment criteria developed by the teacher);

5. conclusion (summing up, prospects for further study of this problem).

After presenting the results, projects are usually posted on the Internet to familiarize other students.

According to T. March, a good educational quest should have an intriguing introduction, a clearly formulated task that provokes higher-order thinking, a distribution of roles that provides different perspectives on the problem, and a reasonable use of Internet sources (Fedorov, 2016).

\section{CONCLUSION}

Web quest help students rise their' self-esteem, solve motivation problems, form the culture of communication and social behavior in general. The work on the web quest introduces students to professional computer skills, makes it possible to realistically assess their communication capabilities, improves academic performance by summarizing, fixing and repeating the training and additional material, organizing its practical application, and eliminating gaps in education.

In the process of creative work, students are involved in research activity. They don't only reproduce ready-made knowledge, but also integrate new ideas, learn to work quickly with information, classifying it, participate in defining their own educational trajectory, prepare for continuous continuing education. 


\section{REFERENCES}

Gorbunova L., Subbotina E. Use of information technologies in the learning process. Young Scientist, 4 (2013), 544.

Altimentova D., Rozhko K. Information technologies in education. Concept, 11 (2016), 826.

Krasovskaya L., Isabelovqa T. Application of information technologies in education. Scientific result. Pedagogy and psychology of education, 3 (2017), 29.

Polat E. New pedagogic and information technologies in the education system, Academia, Moscow, 2017.

Novikova, A. Media educational quests. Innovations in education, 10 (2008), 71.

Fedorov A. Media Education: Creative Tasks for Students and schoolchildren. Innovations in education, 4 (2016), 175. 